\title{
Erratum to: Clinical and biological correlates of adolescent anorexia nervosa with impaired cognitive profile
}

\author{
Susana Andrés-Perpiña $\cdot$ Estefania Lozano-Serra • \\ Olga Puig · Sara Lera-Miguel · Luisa Lázaro • \\ Josefina Castro-Fornieles
}

Published online: 14 June 2014

(C) Springer-Verlag Berlin Heidelberg 2014

Erratum to: Eur Child Adolesc Psychiatry (2011)

\section{0:541-549}

DOI 10.1007/s00787-011-0216-y

In the original publication the second affiliation of Dr. Estefania Lozano-Serra has been inadvertently missed. The other affiliation is given below:

"Department of Psychiatry and Legal Medicine, Universitat Autònoma de Barcelona"

The online version of the original article can be found under doi:10.1007/s00787-011-0216-y.

S. Andrés-Perpiña $(\bowtie) \cdot$ E. Lozano-Serra · O. Puig ·

S. Lera-Miguel · L. Lázaro · J. Castro-Fornieles

Hospital Clinic of Barcelona, Barcelona Spain

e-mail: sandres@clinic.ub.es

E. Lozano-Serra

Department of Psychiatry and Legal Medicine, Universitat

Autònoma de Barcelona, Barcelona, Spain 